BANGLADESH J CHILD HEALTH 2009; VOL 33 (1) : 22-26

\title{
The Efficacy of Subcutaneous Versus Oral Methotrexate in Patients with Juvenile Idiopathic Arthritis
}

\author{
MANIK KUMAR TALUKDER ${ }^{1}$, MOHAMMAD IMNUL ISLAM ${ }^{2}$, MAHMUDA HOSSAIN $^{3}$ \\ SHAHANA AKHTER RAHMAN ${ }^{4}$ \\ Abstract \\ Objective: To investigate the efficacy of subcutaneous versus oral methotrexate in \\ patients with Juvenile Idiopathic Arthritis (JIA) according to ACR 30 improvement criteria. \\ Design: Prospective control trial (Parallel design) study. \\ Setting: This study was carried out in the department of Paediatrics, Bangabandhu \\ Sheikh Mujib Medical University (BSMMU), Dhaka, Bangladesh, during the period \\ from September 2006 to April 2008. \\ Patients: A total of 40 patients participated in the study. They were divided in 2 equal \\ groups (Group A and Group B) alternatively matching with age, sex, and subtypes of \\ the disease. Methotrexate was given orally in group A patients and subcutaneously in \\ group $B$ patients.
}

Results: Amomg the core set variables active arthritis had the highest percentage of improvement in both the groups and laboratory criteria (ESR) showed lowest improvement. According to ACR-30 criteria, improvement rate was higher in the subcutaneous group than oral group (85\% versus 65\%). Side effects of MTX were also less in subcutaneous group than oral group.

Conclusion: From this study it may be concluded that the efficacy of subcutaneous MTX is more than oral MTX in JIA patients.

Key words: Subcutaneous, oral, methotrexate, juvenile idiopathic arthritis.

\section{Introduction}

Juvenile idiopathic arthritis (JIA) is the most common rheumatic disease in childhood and is a significant cause of both short and long term disability ${ }^{1}$.

The aim of modern treatment of JIA is rapid induction of disease control to prevent joint damage, to maximize physical function and to achieve a normal lifestyle ${ }^{2}$. Medications that slow the progression of Rheumatoid arthritis are called disease modifying anti Rheumatic drugs (DMARDs). American College of Rheumatology (ACR) recommends early use of DMARDs, so that they can slow or help inhibition of joint damage.

Commonly used DMARD s are: methotrexate (MTX), sulfasalazine, hydroxychloroquine, leflunomide and cyclosporine. Over the years of clinical use, methotrexate has transformed the outlook of children

1. Paediatrician, Dhaka

2. Junior consultant (Paediatrics), Begum Khaleda Zia Medical College and Shaheed Suhrawardy hospital, Dhaka

3. Associate Professor, Department of Paediatrics, International Medical College and Hospital, Gushulia, Tongi, Gazipur

4. Professor of Paediatrics, Bangabandhu Sheikh Mujib Medical University, Dhaka

Correspondence: Dr. Manik Kumar Talukder with $\mathrm{JIA}$, and it is considered as the gold standard therapy for patients in juvenile idiopathic arthritis ${ }^{2,3}$.

Several studies reported that parenteral administration of MTX is more effective than oral2,4. Many studies were done for comparing the efficacy and tolerance of subcutaneous (S/C) and intramuscular (I/M) methotrexate. These studies found that subcutaneous route was more convenient, less painful and easier to administer than intramuscular route, though efficacy of both the routes was similar ${ }^{5,6}$.

JIA is quite common in our country. No study so far has been done regarding its treatment with subcutaneous methotrexate. This study was designed to compare the efficacy of subcutaneous MTX with oral MTX in JIA patients.

\section{Materials and Methods}

This was a prospective control trial >ýparallel design) study done in the depertment of paediatrics, Bangabandhu Sheikh Mujib Medical University (BSMMU), Dhaka, during the period of September 2006 to February 2008.

Patients above 7 years with polyarticular and systemic onset JIA fulfilling the criteria according to ILAR 
classification (1999), attending inpatient department and Rheumatology follow-up clinic run by department of Paediatrics, BSMMU were enrolled in the study. Forty six patients were included in the study, but 40 patients completed their regular follow-up. Patients who received any DMARDs or steroid in the previous three months were excluded from the study. Having any renal or hepatic impairment were also excluded from the study.

Verbal consent was taken from the parents/attendants before enrollment of their child in the study. Prior to that they had been informed about the nature of the study. A total number of 46 patients were included in the study. They were divided into 2 equal groups (Group A and Group B). Group A and Group B were divided alternatively matching age, sex, and subtypes of the disease. When matching was not found, we waited till next matching case for enrollment.

Group A patients were given tablet methotrexate (Tab. MTX-2.5mg) orally at a dose of $10 \mathrm{mg} / \mathrm{m}^{2} /$ week as single dose in empty stomach 2 hour before meal. Group B patients were given injection MTX by subcutaneous (s/c) route once weekly, at a dose of $10 \mathrm{mg} / \mathrm{m}^{2} /$ week as a single dose. Oral MTX and injectable MTX given to our patients were prepared by the same company (CHOOKNGWAE pharma corporation, Seoul, Koria). Insulin syringe (1 $\mathrm{ml}=100$ unit) was used for giving S/C MTX in our patients. Site of injection was anterolateral thigh in majority of patients and in forearm in some patients. Before injection, skin of thigh /forearm was cleaned with plain water and cotton. First injection in all the patients were given by the investigator himself. Parents or other attendants were trained the technique of S/C injection. Subsequent injections were given by them.

Along with MTX (Both the groups), prednisolone at a dose of 0.5 to $1 \mathrm{mg} / \mathrm{kg} /$ day and /or Non steroidal antiinflammatory drugs (NSAID) was added for 4 to 6 weeks. The choice of NSAID was naproxen at a dose of $10 \mathrm{mg} / \mathrm{kg} / \mathrm{day}$. Then NSAID was stopped and prednisolone was gradually tapered off over 8 to 12 weeks. No patients received prednisolone or naproxen after 3 months.

Disease activity measures were assessed at the time of diagnosis as base line. Follow up of the patients were done at 4 week, 12 week and 24 weeks of treatment. Relevent investigations were done during initial visit and follow up visits. Two patients from group $A$ and 3 patients from group $B$ did not complete their regular follow up. For keeping equal number in both the groups one patients from group A was excluded randomly.
At the end of 24 weeks, rate of improvement according to ACR-30 criteria was compared between Group A (oral) and Group B (s/c). Assessment of all the patients were done by the same person (by the investigator himself). Core set of outcome measure were assessed according to ACR recommendations ${ }^{7,8}$.

Permission for the study was taken from the concerned department and authorities.

\section{Results}

At follow up of Group A (oral) patients, improvement of most parameters were found at 4 weeks, 12 weeks and 24 weeks. Active arthritis showed maximum improvement (75\%, 75\% and $85 \%$ respectively), according to ACR-30 improvement criteria (Table-I).

Table-I

Improvement status of different parameters according to ACR-30 criteria at 4 wekks, 12 weeks and 24 weeks from base line in Group A $(n=20)$

\begin{tabular}{lccc}
\hline Parameters & \multicolumn{3}{c}{ Number (Percentage) } \\
\cline { 2 - 4 } & 4 weeks & 12 weeks & 24 weeks \\
\hline Active arthritis & $15(75 \%)$ & $15(75 \%)$ & $17(85 \%)$ \\
Limited range of & $11(55 \%)$ & $14(70 \%)$ & $16(80 \%)$ \\
movement & & & \\
VAS patients/parents & $13(65 \%)$ & $13(65 \%)$ & $13(65 \%)$ \\
VAS physician & $13(65 \%)$ & $13(65 \%)$ & $13(65 \%)$ \\
CHAQ-B & $11(55 \%)$ & $13(65 \%)$ & $13(65 \%)$ \\
ESR & $8(40 \%)$ & $17(85 \%)$ & $13(65 \%)$ \\
\hline
\end{tabular}

At follow up of the Group-B (s/c) patients most of the parameters were improved at 4 weeks, 12 weeks and 24 weeks. Maximum improvement was found in active arthritis (75\%, 85\% and 90\% respectively) according to ACR-30 improvement criteria (Table-II).

\section{Table-II}

Improvement status of different parameters according to ACR-30 criteria at 4 weeks, 12 weeks and 24 weeks from base line in Group B $(n=20)$

\begin{tabular}{lccc}
\hline Parameters & \multicolumn{3}{c}{ Number (Percentage) } \\
\cline { 2 - 4 } & 4 weeks & 12 weeks & 24 weeks \\
\hline Active arthritis & $15(75 \%)$ & $17(85 \%)$ & $18(90 \%)$ \\
Limited range of & $13(65 \%)$ & $17(85 \%)$ & $17(85 \%)$ \\
movement & & & \\
VAS patients/parents & $13(65 \%)$ & $15(75 \%)$ & $15(75 \%)$ \\
VAS physician & $15(75 \%)$ & $15(75 \%)$ & $17(85 \%)$ \\
CHAQ-B & $11(55 \%)$ & $15(75 \%)$ & $15(75 \%)$ \\
ESR & $13(65 \%)$ & $14(70 \%)$ & $13(65 \%)$ \\
\hline
\end{tabular}


After 24 weeks of treatment, active arthritis was improved in $85 \%$ and $90 \%$ cases in Group Aand Group $B$ respectively. Limited range of motion was improved in $80 \%$ and $85 \%$ cases respectively. Visual analog scale (VAS) (parents) and VAS (physician) improvement was present in $65 \%$ versus $75 \%$ and $65 \%$ versus $85 \%$ cases in Group A and Group B respectively. Functional ability assessed by using Childhood Health Assessment Questionnaire (CHAQB) was improved in $65 \%$ cases in group $A$ and $75 \%$ cases in group B. ESR became normal in $65 \%$ cases in both the groups (Table-III).

\section{Table-III}

Improvement of different parameters according to ACR-30 at 24 weeks in both the groups $(n=20+20)$

\begin{tabular}{lccc}
\hline Parameters & $\begin{array}{c}\text { Number (\%) } \\
\text { Group A (oral) }\end{array}$ & $\begin{array}{c}\text { Number (\%) } \\
\text { Group B(s/c) }\end{array}$ & $\begin{array}{c}\mathrm{p} \\
\text { value* }\end{array}$ \\
\hline Active arthritis & $17(85.0)$ & $18(90.0)$ & 1.00 \\
Limited movement & $16(80.0)$ & $17(85.0)$ & 1.00 \\
CHAQ & $13(65.0)$ & $15(75.0)$ & 0.73 \\
VAS patient/parents & $13(65.0)$ & $15(75.0)$ & 0.73 \\
VAS Physician & $13(65.0)$ & $17(85.0)$ & 0.144 \\
ESR & $13(65.0)$ & $13(65.0)$ & 1.00 \\
\hline
\end{tabular}

*Chi square test was done to measure the level of significance and where necessary

Yates correction was done.

During final follow up visit (at 24 weeks), $65 \%$ of JIA patients treated with oral MTX had improvement according to ACR-30 criteria. On the other hand 85\% cases treated with subcutaneous MTX had improvement (Table-IV).

\section{Table-IV}

Improvement status at 24 weeks in both the groups according to $A C R-30(n=20+20)$

\begin{tabular}{lccc}
\hline Improvement & \multicolumn{2}{c}{ Number (percentage) } & $\mathrm{p}$ \\
\cline { 2 - 3 } status & Group A & Group B & value $^{\star *}$ \\
\hline Improved & $13(65.0)$ & $17(85.0)$ & 0.144 \\
Not improved & $7(35.0)$ & $3(15.0)$ & \\
Total & $20(100.0)$ & $20(100.0)$ & \\
\hline
\end{tabular}

${ }^{*} \chi^{2}$ value $=2.31, \mathrm{df}=1, \mathrm{p}=0.144$
It was found that gastrointestinal (GIT) toxicities like nausea, vomiting, abdominal discomfort were more common in oral groups. Increased liver enzyme (ALT) was found in 3 cases ( 2 among Group A and 1 among Group B). In all the 3 cases ALT level was more than 2 fold of upper limit of normal. Though frequency of side effects were about double in oral group, but these were not statistically significant (Table-V).

\section{Table-V}

Side effects of MTX $(n=20+20)$

\begin{tabular}{lccc}
\hline Side effects & \multicolumn{2}{c}{ Number (percentage) } & $p$ \\
\cline { 2 - 3 } & Group A & Group B & value \\
\hline Headache & $4(20.0)$ & $2(10.0)$ & 0.658 \\
Nausea & $6(30.0)$ & $3(15.0)$ & 0.45 \\
Vomiting & $5(25.0)$ & $3(15.0)$ & 0.693 \\
Abdominal discomfort & $4(20.0)$ & $2(10.0)$ & 0.658 \\
Increased liver enzyme & $2(10.0)$ & $1(5.0)$ & 1.00 \\
\hline
\end{tabular}

${ }^{* *}$ Chi square test (with Yates correction) was done to measure the level of significance

\section{Discussion}

This study was carried out with the aim to asses and compare the efficacy of oral methotrexate and subcutaneous methotrexate in juvenile idiopathic arthritis patients. Of the total 46 patients included in this study, 40 (20 in the oral and 20 in the subcutaneous group) completed 24 weeks treatment. As most of the oligoarticular JIA patients respond to intra-articular steroid and NSAIDs, so only polyarticular and systemic onset patients were included in this study.

When improvement of different core set variables according to ACR-30 were analysed individually, improvement of active arthritis was highest (90\% in Group B and 85\% in Group A). Minimum improvement was found in the laboratory variables (ESR). In both the groups ESR was improved in $65 \%$ cases. There was improvement of all the 6 core set variables at 4 weeks and 12 weeks also (Table I, II) in both the oral and subcutaneous group. But this study did not consider it important, because all the patients received oral prednisolone or NSAID upto 8 to 12 weeks of treatment. So, this improvement could also be due to prednisolone and NSAIDs. As because at final follow up the patients of both the groups (Goup A and Group 
B) were only on MTX, so at that time the improvement was due to MTX only (Table III). Islam et $\mathrm{al}^{9}$ found similar finding in their study. They found that highest improvement was present in active arthritis and lowest in ESR (77.5\%). Ruperto et $\mathrm{al}^{10}$ also found similar type of improvement. In their study ESR was improved in $59 \%$ cases which was also lowest. Though statistically not significant, percentage improvement of all other core set variables (limited range of motion, CHAQ-B, VAS physician and VAS parents) were higher in subcutaneous group than oral group in this study.

When improvement status of orally treated group was compared with subcutaneously treated group at final follow up, percentage improvement according to ACR30 criteria was $65 \%$ and $85 \%$ respectively (Table-IV). Though statistically not significant, percentage improvement was much higher in the subcutaneous group than oral group. One probable explanation for the higher efficacy of S/C MTX could be due to increased bioavailability of MTX by the parenteral route. This could also be due to the fact that there was better adherence to MTX therapy when it was given by parenteral route. As because parenterally treated patients had less side effects, this also could be a contributing factor for better compliance. Braun et al ${ }^{11}$ in their study done with adult Rheumatoid arthritis patients, showed that statistically significant difference was found between oral and subcutaneously treated patients according to ACR-20 criteria. But while using ACR-50 and ACR-70 criteria they did not find any significant difference. In paediatric population ACR30 is widely accepted ${ }^{11}$. No comparative study between oral and subcutaneous MTX therapy in JIA patients so far had been done using ACR-30 criteria, though use of subcutaneous MTX is widely accepted and advocated ${ }^{1,12,13}$.

The present study found that 9 patients ( 6 patients in oral group and 3 patients in subcutaneous group) experienced one or more side effects of MTX (TableV). Though side effects were much higher in the oral group than subcutaneous group, it was not statistically significant. Significant difference was not found between two groups perhaps because of small sample size. Transient increase of liver enzyme (ALT) was present in two patients in the oral group (160 U/L and $96 \mathrm{U} / \mathrm{L}$ ) and one in the subcutaneous group (120 U/ L), which became normal within two weeks. None of the side effects mentioned above needed discontinuation of MTX therapy. Hoekstra et $\mathrm{al}^{14}$ found that $37 \%$ had history of nausea, $24 \%$ had headache and $10 \%$ had increased liver enzyme in their study. Cassidy and petty found abdominal discomfort and nausea in $12 \%$ of patients and increased liver enzyme in $9 \%$ of patients treated with MTX in JIA patients ${ }^{15}$. Our study showed more or less consistent side effects with these studies.

\section{Conclusion}

From this study it may be concluded that the efficacy of subcutaneous MTX is more than oral MTX in JIA patients according to ACR-30 improvement criteria. Side effects of methotrexate were also less in subcutaneous group than oral group.

\section{References}

1. Jennifer EW, Norman TI. Juvenile Idiopathic Arthritis. Paediatr Clin N Am 2005; 52: 413-42.

2. Ramanan AV, Whitworth $P$, Baildam EM. Use of methotrexate in juvenile idiopathic arthritis. Arc Dis Child 2003; 88: 197-200.

3. Ravelli A, Martini A. Methotrexate in Juvenile Idiopathic Arthritis. J Rheumatol 2000; 27: 183033.

4. Ravelli A, Gerloni V, Corona F, Falcini F, Lepore L, De Sanctis R, et al Oral versus intramuscular methotrexate in juvenile idiopathic arthritis. Clin Exp Rheumatol 1998; 16: 181-83.

5. Brooks PJ, Spruill WJ, Parish RC, Birchmore DA. Pharmacokinetics of low dose methotrexate in Rheumatoid arthritis patients. Arthritis Rheum 1990; 33: 91-94.

6. Royal College of Nursing. Administering subcutaneous methotrexate for inflammatory arthritis. RCN guidance for nurses; London: Wyeth: 2004.

7. Felson DT, Anderson JJ, Bores M, Bombardier C, Chernoff M, Fried B, et al. The American college of Rheumaology preliminary core set of disesse activity measure of Rheumatoid arthritis clinical trial. Arthritis Rheum 1993; 36: 729-40.

8. Giannini EH, Ruperto N, Ravelli A, Lovell DJ, Felson DT, Martini A. Preliminary definition of improvement in juvenile arthritis. Arthritis Rheum 1997; 40: 1202-09.

9. Islam MI, Hossain M, Rahman SA. Performance of the preliminary definition of improvement in 
juvenile idiopathic arthritis patients treated with methotrexte; experience from Bangladesh. International Journal of Rheumatic Disease; 2008: 11: 241-45.

10. Ruperto N, Ravelli A, Falcini F, Lepore L, De sanctis R, Zullian F, et al. Performance of the preliminary definition of improvement in juvenile chronic arthritis patients treated with methotrexate. Ann Rheum Dis 1998; 57: 38-41.

11. Braun J, Kaestner P, Flaxenberg P, Waehrisch J, Hanke P, Demary W, et al. The efficacy and safety of subcutaneous (S.C.) versus oral application of methotrexate (MTX) in patients with active Rheumatoid Arthritis (RA)- Results of a randomized, controlled, double-blind, multi-centre study. http://www.hopkins-arthritis. som.jhmi.edu/ edu/eular2006 accessed on March 2007.
12. Arthur V, Jubb R, Homer D. A study of parenteral use of methotrexate in Rheumatic conditions. Journal of Clinical Nursing 2002; 11: 256-63.

13. Wallace CA. The use of methotrexate in childhood Rheumatic disease. Arthritis Rheum 1998; 41: 381-91.

14. Hoekstra M, Van Ede EA, Haagsma J C, Van de laar FAM, Huizinga J WT, Kruijsen MWM, et al. Factors associated with toxity, final dose, and efficacy of methotrexate in patients with Rheumatoid arthritis. J Rheumatol 2002; 29: 2084-91.

15. Cassidy JT, Petty RE. Juvenile Rheumatoid Arthritis. In: Cassidy JT, Petty RE, editors. Textbook of Paediatric Rheumatology. $4^{\text {th }}$ ed. Philadelphia: W.B Saunders; 2001. P. 214-95. 